\title{
Survey on Student Attitude Towards Science Education in English Textbooks of Chinese Senior High School from the Perspective of Multimodality
}

\author{
Bin Lu ${ }^{1,2, *}$, Shengyan Shi' \\ ${ }^{1}$ School of Management, Shinawatra University, Bangkok, Thailand \\ ${ }^{2}$ School of Foreign Languages, Luoyang Normal University, Luoyang, China \\ Email address: \\ 2423905702@qq.com (Bin Lu),2118903450@qq.com (Shengyan Shi) \\ ${ }^{*}$ Corresponding author
}

To cite this article:

Bin Lu, Shengyan Shi. Survey on Student Attitude Towards Science Education in English Textbooks of Chinese Senior High School from the Perspective of Multimodality. Education Journal. Vol. 10, No. 1, 2021, pp. 23-34. doi: 10.11648/j.edu.20211001.14

Received: January 25, 2021; Accepted: February 1, 2021; Published: February 10, 2021

\begin{abstract}
Since the 1990s, with the development of science and technology, multimodal features have become more and more obvious, and multimodal discourse research has developed rapidly to explore how various modals of discourse interact to produce meaning. Among the discourse types studied by multimodality, educational discourse accounts for a small proportion. English textbooks of Chinese senior high school, as one of the important educational discourses, the teaching contents of science education, especially, the reasonable arrangement, integration forms of science education have positive significance to improve students' scientific literacy. This study aims to investigate Chinese students' attitude towards science education from the perspective of multimodality by qualitative and quantitative methods; explores the factors that influence different attitudes and opinions of students towards science education in English textbooks of Chinese senior high school; and puts forward some suggestions on using multimodality to teach science education. A total of 300 students from senior high school A (150) and B (150) of Xuchang city, a Chinese city, were investigated. The findings are: 1) students prefer the combination of audios, videos, images, colors and texts to be used in English learning; 2) students hope that they can learn more knowledge about science education systematically under the use of multimodality. The suggestions are: 1) it should pay attention to the significance of necessity of science education in English textbooks of Chinese senior high school; 2) it should pay attention to help student to learn science education by using multimodality technology for their future scientific competence; 3 ) it should pay attention to learn and teach science education systematically; 4) it should pay attention to enrich teachers' teaching competence and technology skills when using multimodality to teach educational contents.
\end{abstract}

Keywords: Chinese Science Education, English Textbooks, Senior Students, Attitude Survey, Multimodality

\section{Introduction}

Multimodal teaching is believed that it is far better than traditional teaching, which can stimulate students' interest in learning and attract students' attention. In recent 10 years, some researchers have carried out empirical research on multimodal teaching in vocabulary, reading, speaking, writing by methods of experiments, questionnaires and interviews. Yu Bi [1] takes the students of No.66 middle school in Urumqi as a case to study the learning effects of multimodal discourse analysis in vocabulary, and Liuyan Xin [2], Wenwen Qu [3], Xiaoxian Liao [4] also do familiar study with the difference stage and period of students. Xue Chen carries out a study of college English writing instruction based on multimodality [5]. In addition, some researchers of systematic linguistics also applies a discourses research of English textbooks based on multimodal discourse analysis. In the stage of Chinese senior high school, Juan Du has made a multimodal discourse analysis on the texts of English textbooks in Chinese senior high school published by Beijing Normal University Publishing House (BNUPH) by means of text analysis and qualitative and quantitative methods based on the theory of visual grammar and intersemiotic complementarity [6]. It is found that the images in English textbooks of Chinese senior high school published by BNUPH fully realize the three 
visual meanings, and cooperate with the text to construct the meaning. In the meaning of image representation, narrative reproduction is the main representation process; in the interactive meaning, the images in this textbook mainly rely on the perspective of providing, social distance and positive equality; the image does not highlight the significance by the central position, mainly depends on the text. Based on the framework of multimodal discourse analysis and the relationship between images and texts, Weiqing Cui, starting from qualitative and quantitative research methods, has five impacts on students' learning, namely, students' cognition, sensitivity and utilization of multimodal resources in textbooks, teachers' guidance of multimodal resources in textbooks and their modal awareness of current students to have a certain understanding of the real modal reading ability of students in Chinese senior high school, a questionnaire survey was conducted. The survey results show that students' sensitivity and utilization of multimodality in textbooks and teachers' guidance on multimodality have a large improved space. Therefore, it is necessary to use textbooks to improve students' multimodal reading ability. Then it analyzes the text, image modal and the relationship between images and texts in the pre-reading and reading parts of English textbooks in Chinese senior high school published by People's Education Press, in order to have a more comprehensive understanding of the multimodal meaning construction in the text and help teachers and students make full use of the multimodal resources of textbooks for teaching and learning [7].

The discourse of science education has become one of the research hot spots under the background of the world epidemic era [8]. As an important educational material, the research of science discourse in English textbook plays an important role in Chinese senior high school. Students are the main objectives of English textbooks which can form cognition understandings towards all kinds of new society problems with science education knowledge. This study focuses on the the attitude study of students towards science education in English textbooks of Chinese senior high school from the perspective of multimodality, and the contents of science education adopting external evaluation of Cheng Xiaotang's textbook analysis theory [9] and based on the former research outcomes of contents, integration forms, meaning construction, relation between image and text by using qualitative methods and investigate the attitude of teachers towards science education in Chinese English textbooks of Chinese senior high school published by PEP (People's Education Press), BNUPH (Beijing Normal University Publishing House) and FLTRP (Foreign Language Teaching and Research Press) by using quantitative methods from the perspective of multimodality based on textbook evaluation theory, visual grammar, and relation theory of image and text the former research outcomes of the researcher's study on multimodality [10].

\subsection{Research Significance}

In terms of theoretical significance, this study is to promote the theoretical innovation of multimodality. As an important resource of classroom teaching, textbook compilation and reform need to consider many factors for improve the education quality. In view of the prominent characteristics of contemporary subject education textbooks, multimodal research provides a theoretical basis for the compilation work, which can help editors decide what types of images to choose in textbooks, what ratio relationship to maintain between different types of images, and what kind of relationship should be established between images and text parts. In terms of practical significance, it can promote the innovation of multimodal teaching. Multimodality, the combination of audio, video, image, color, and etc., is "the symbolic resource of expressing meaning shaped by social culture" [11]. Multimodal teaching is better than traditional teaching because it can stimulate students' interest in learning and attract students' attention compared with traditional teaching. Multimodal research also promotes the overall reform of basic education curriculum textbooks in China to some extent [12].

\subsection{Main Concepts}

It is the core for a scientific research to identify the concept of terms. Concept, also known as definition, is a precise and brief explanation of the essential characteristics of a thing. To form a comprehensive understanding on the core concepts can help form a scientific cognition for research and obtain the scientific research results. Science education and scientific literacy, modality, mode and medium are two groups of similar concepts.

Science education and scientific literacy. Science education is aimed at imparting natural science knowledge, cultivating scientific spirit, developing the understanding of objective world law and improving the ability to transform the material world. Scientific literacy is one of the important contents of core literacy. Science education should be an educational activity with science and the cultivation of people's scientific literacy as the core [13].

Modality, mode and medium. Mode refers to the mode of discourse, which is one of the three elements of the context and is juxtaposed with the field and tenor of discourse by systemic functional linguists. It means channel of communication, such as spoken mode, written mode, electronic mode, and so on. To a certain extent, the use and change of these modes affect the information flow, and ultimately affect the texture, which is the characteristic of discourse. Medium refers to the technology used in language communication, which is not a term in the sense of strict linguistic and semiotic. Modality refers to the communication channels and media, including language, technology, image, color, music and other symbol systems [14-16].

\section{Research Design}

\subsection{Research Problems}

This study mainly explores the following three research problems:

1) What are the attitude of students towards science education in English textbooks of Chinese senior high school from the perspective of multimodality? What 
kind of language and symbols with audio, video, image and color of multimodality the students prefer most?

2) What are the factors influencing different attitudes and opinions of students towards science education in English textbooks of Chinese senior high school from the perspective of multimodality?

3) What are the suggestions on how to improve the students' efficiency of learning science education and scientific technology from the perspective of multimodality?

\subsection{Research Objectives}

The research objectives are following:

1) To explore the factors that influence different attitudes and opinions of students through the correlation between students' basic information and the attitudes towards science education in English textbooks of Chinese senior high school;

2) To investigate students' attitude towards interactive relation between language and symbols with audio, video, image and color of multimodality on science education of English textbook in Chinese senior high school;

3) To puts forward some suggestions on multimodality teaching strategy in science education.

\subsection{Research Content}

\subsubsection{Attitude of Students Towards Multimodality Forms in English Textbooks}

This research provides a group of discussion from questionnaire survey to understand the attitude of Chinese students towards the integration of multimodality in English textbooks of Chinese senior high school and the different symbols of audio, video, image and color of multimodality forms in English class teaching.

\subsubsection{Attitude of Students Towards Science Education in Class Teaching}

The research provides the attitude of Chinese students towards the likes and dislikes of the scientific education design in English class teaching of Chinese senior high school and some suggestions on improvement of learning effect between student and English textbooks.

\subsection{Research Methods}

This study chooses mix methods of qualitative and quantitative descriptive statistics including correlations, independent sample $\mathrm{T}$ test, frequency, percentage, mean and standard deviation to explain details of demographic profiles of the respondents and behavior. Quantitative data obtained from survey questionnaires will be collected, deleted results with missing values in the questionnaire and coded in software Excel, calculated frequency, percentage, mean and standard deviation by using descriptive statistics to analyze and explain personal profiles of the respondents, using correlation analysis to test the factors influencing students' attention towards science education in English textbooks of Chinese senior high school through software SPSS 26.0.

\subsection{Research Hypothesis}

Six hypotheses have been set for study purpose. All these are as following:

H1: There is significant difference between the two schools in students' attitude towards science education in English textbooks of Chinese senior high school.

$\mathrm{H} 2$ : There is less positive correlation between the students with different school and the attention of science education in English textbooks of Chinese senior high school.

H3: There is less positive correlation between the students with different gender and the attention of science education in English textbooks of Chinese senior high school.

H4: There is less positive correlation between the students with different grade and the attention of science education in English textbooks of Chinese senior high school.

H5: There is less positive correlation between the students who have ages and the attention of science education in English textbooks of Chinese senior high school.

H6: There is less positive correlation between the students with different class types and the attention of science education in English textbooks of Chinese senior high school.

\subsection{Data Collecting Method}

The methods to collect data are following:

1) To design the questionnaire survey of students on platform of questionnaire;

2) To carry out the survey research of students' attitude towards science education from the perspective of multimodality in English textbooks of Chinese senior high school;

3) To collect the data and data analysis.

The design of students' questionnaire using Likert scale (Level 5) includes 6 parts mainly: the first is basic information survey of the participants; the second is the students' attitude towards necessity of science education in English textbooks of Chinese senior high school; the third is students' attitude towards the content of science education in English textbooks of Chinese senior high school; the forth is students' attitude towards the integration forms of science education in English textbooks of Chinese senior high school; the fifth is students' attitude towards content and integration forms of science education that they prefer; the sixth is students' attitude towards their teachers' teaching competence of using multimodality to teach the science education of English textbooks in Chinese senior high school.

Part 1. Basic personal information of gender, age, grade and class type;

Part 2. Questions related to necessity of science education in English textbooks of Chinese senior high school and a total of 4 questions;

Part 3. Questions related to content of science education in English textbooks of Chinese senior high school and a total of 3 questions;

Part 4. Questions related to integration forms of science education in English textbooks of Chinese senior high school and a total of 7 questions;

Part 5. Questions related to students' preferences towards 
science education in English textbooks of Chinese senior high school and a total of 3 questions;

Part 6. Questions related to teaching competence of using multimodality to teach science education of English textbooks in Chinese senior high school and a total of 3 questions;

Of these, there are 20 single choice questions related to the students' attitude about science education in the English textbook of Chinese senior high school using 5 scale of Likert's scale to investigate from part 2 to part 6 , and the principle of scoring including " 1 "refers to "strongly disagree", "2" refers to "disagree", "3" refers to "not sure", "4" refers to "quite agree", "5" refers to "strongly agree".

\section{Data Analysis and Discussion}

Cheng Xiaotang's textbook analysis theory proposed that textbooks should be analyzed from internal evaluation and external evaluation[17]. Internal evaluation is the analysis and evaluation of the guiding ideology, components, arrangement of textbooks' contents, the authenticity of textbooks' language materials, the design and the evaluation of textbooks; external evaluation is to evaluate textbooks for a certain user group. The former research on science education in China English textbooks of senior high school from the perspective of multimodality from internal evaluation, namely, English teachers attitudes towards science education in English textbooks of Chinese senior high school have carried out and acquired some outcomes. English teachers are one of the main users in a certain user group, so are the students. Therefore, this study mainly focuses on students' attitudes towards multimodality and science education in English textbooks of Chinese senior high school. The following are the data analysis of this survey research, it intends to explore the influencing factors that students' attitudes towards science education in
English textbooks of Chinese senior high school from the perspective of multimodality.

\subsection{Reliability Statistics and Validity Analysis of Questionnaire}

Table 1. Reliability analysis of students' questionnaire.

\begin{tabular}{ll}
\hline Reliability Statistics & \\
\hline Cronbach's Alpha & N of Items \\
0.869 & 20 \\
\hline
\end{tabular}

According to the above table, the Cronbach's Alpha is $0.869(0.869>0.8)$. According to the Cronbach's Alpha of reliability statistics, this scale has good reliability.

Table 2. Validity analysis of students' questionnaire.

\begin{tabular}{|c|c|c|}
\hline \multicolumn{3}{|l|}{ KMO and Bartlett's Test } \\
\hline Kaiser-Meyer-Olkin Measu & f Sampling Adequacy. & 0.866 \\
\hline \multirow{3}{*}{ Bartlett's Test of Sphericity } & Approx. Chi-Square & 2592.372 \\
\hline & df & 190 \\
\hline & Sig. & .000 \\
\hline
\end{tabular}

It can be seen from the above table that the value of kmo sampling appropriateness is $0.866(0.866>0.8)$. According to the validity regulations, the validity of the questionnaire is quite good, that is, the questionnaire is effective. The $p$ value of significance is $0.000(0.000<0.001)$, that is to say, the level of significance is reached, and factor analysis can be done.

\subsection{Correlation Analysis of Basic Information and Attention (Total Score)}

Correlation analysis is a statistical method used to study the interdependence and close relationship between variables. There are many factors influencing the formation of attitude towards science education in this survey, such as school, gender, age, grade and class type.

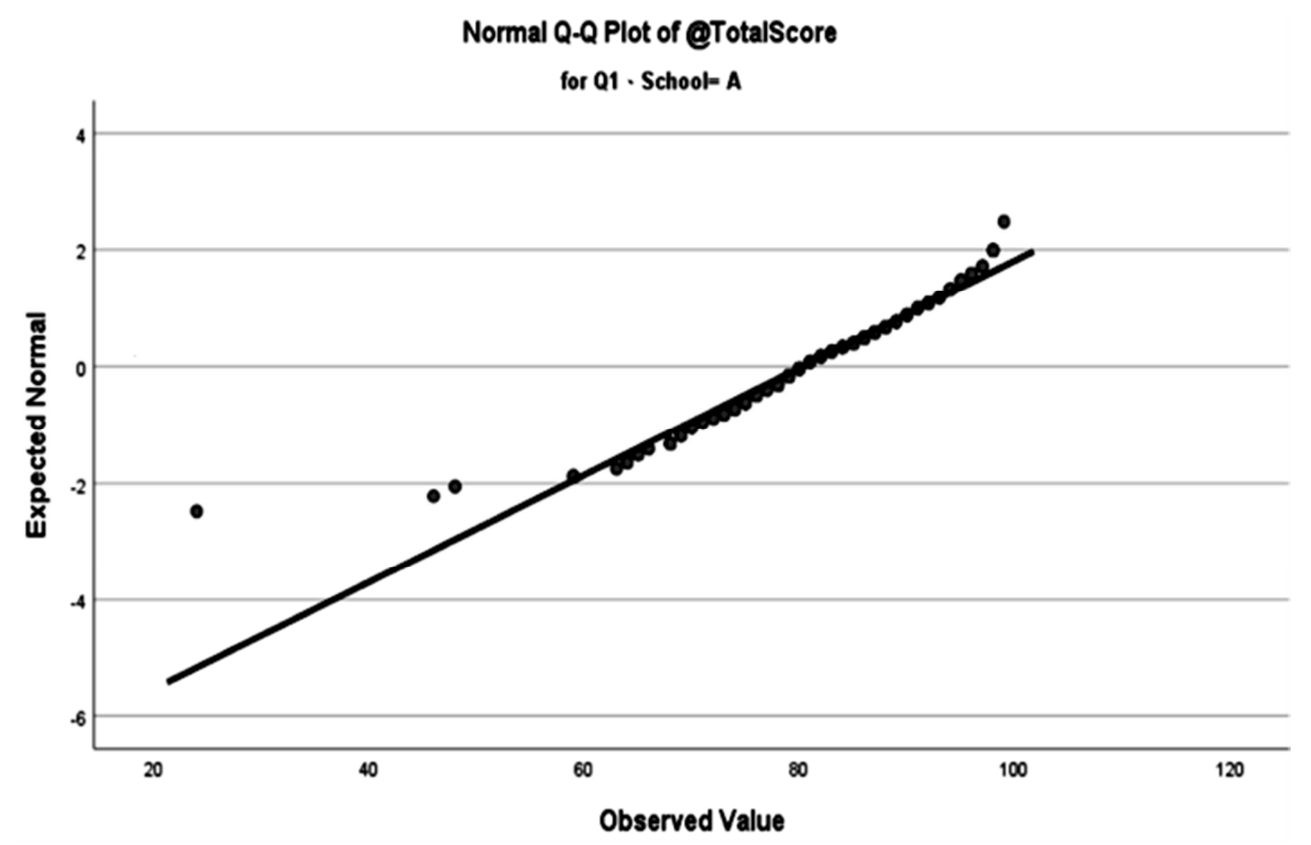

Figure 1. Normal Q-Q Plot of Score for School A. 
Table 3. Basic information of students.

\begin{tabular}{llll}
\hline Classification & & Frequency & Percentage \\
\hline \multirow{2}{*}{ School } & $\mathrm{A}$ & 150 & $50.0 \%$ \\
& $\mathrm{~B}$ & 150 & $50.0 \%$ \\
Grade & Senior 1 & 140 & $46.7 \%$ \\
& Senior 2 & 160 & $53.3 \%$ \\
Gender & Male & 101 & $33.7 \%$ \\
& Female & 199 & $66.3 \%$ \\
& 14 years old & 5 & $1.7 \%$ \\
Age & 15years old & 88 & $29.3 \%$ \\
& 16years old & 150 & $50.0 \%$ \\
& 17years old & 55 & $18.3 \%$ \\
Class type & 18years old & 2 & $0.7 \%$ \\
Total & Liberal Art & 157 & $52.3 \%$ \\
& Science & 143 & $47.7 \%$ \\
\hline
\end{tabular}

school B participating in the questionnaire survey are mainly from Xuchang, He'nan Province in China. Due to the heavy academic pressure faced by students of senior three, the students surveyed in this study are mainly in senior 1 and senior 2. Among them, students of senior 1 account for $46.7 \%$ and senior 2 account for $53.3 \%$; males account for $33.7 \%$ and females $66.3 \%$; the age is concentrated on 15,16 and 17 years old; the number of students from liberal art major class accounts for $52.3 \%$ and science major class accounts for $47.7 \%$. Then the independent sample t-test needs to meet the conditions that the two groups of variables obey or obey the normal distribution approximately and the variance should be homogeneous, the data as following figures:

From figure 1 and 2 above, it can be seen that the two groups of variables, school A and school B, are normally distributed approximately.

As can be seen from table 300 students from school A and

Normal Q-Q Plot of @TotalScore

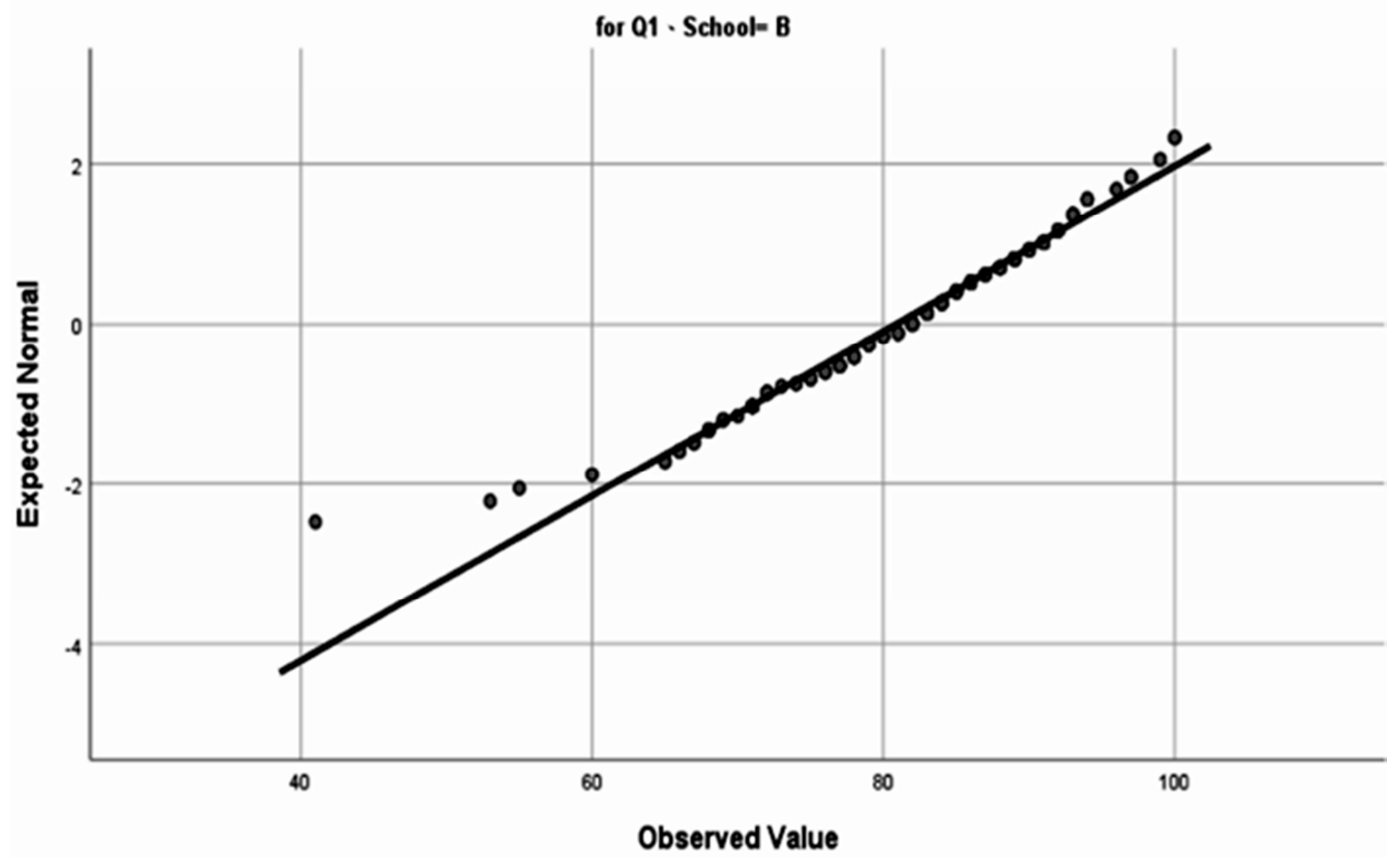

Figure 2. Normal Q-Q Plot of Score for School B.

Table 4. Independent Samples Test.

\begin{tabular}{|c|c|c|c|c|c|c|c|c|c|c|}
\hline \multicolumn{11}{|c|}{ Independent Samples Test } \\
\hline & & \multicolumn{2}{|c|}{$\begin{array}{l}\text { Levene's Test for } \\
\text { Equality of Variances }\end{array}$} & \multicolumn{7}{|c|}{ T-test for Equality of Means } \\
\hline & & \multirow[t]{2}{*}{$\mathbf{F}$} & \multirow[t]{2}{*}{ Sig. } & \multirow[t]{2}{*}{$\mathbf{t}$} & \multirow[t]{2}{*}{ df } & \multirow{2}{*}{$\begin{array}{l}\text { Sig. } \\
\text { (2-tailed) }\end{array}$} & \multirow{2}{*}{$\begin{array}{l}\text { Mean } \\
\text { Difference }\end{array}$} & \multirow{2}{*}{$\begin{array}{l}\text { Std. Error } \\
\text { Difference }\end{array}$} & \multicolumn{2}{|c|}{$\begin{array}{l}95 \% \text { Confidence Interval } \\
\text { of the Difference }\end{array}$} \\
\hline & & & & & & & & & Lower & Upper \\
\hline \multirow{2}{*}{ Score } & Equal variances assumed & .501 & .480 & -.498 & 298 & .619 & -.59333 & 1.19161 & -2.93837 & 1.75171 \\
\hline & Equal variances not assumed & & & -.498 & 294.109 & .619 & -.59333 & 1.19161 & -2.93850 & 1.75183 \\
\hline
\end{tabular}

Table 4 is the results of independent samples test for that "Is there significant difference between the two schools in students' attitude towards science education in high school English textbooks", it can be seen that P (sig.) is $0.480>0.05$, so the variance is homogeneous. Hypothesis 1 is that "There is significant difference between the two schools in students' attitude towards science education in high school English textbooks". In other words, it shows that there is a significant difference in the overall mean value represented by the two groups of samples if $\mathrm{P}$ is less than 0.05 ; it shows that there is no difference if $\mathrm{P}$ is more than 0.05 and the original hypothesis cannot be rejected. 
Table 5. Group Statistics of School A and School B.

\begin{tabular}{llllll}
\hline \multicolumn{6}{c}{ Group Statistics } \\
& School & N & Mean & Std. Deviation & Std. Error Mean \\
\hline \multirow{2}{*}{ Score } & A & 150 & 80.2600 & 10.89697 & 0.88973 \\
& B & 150 & 80.8533 & 9.70808 & 0.79266 \\
\hline
\end{tabular}

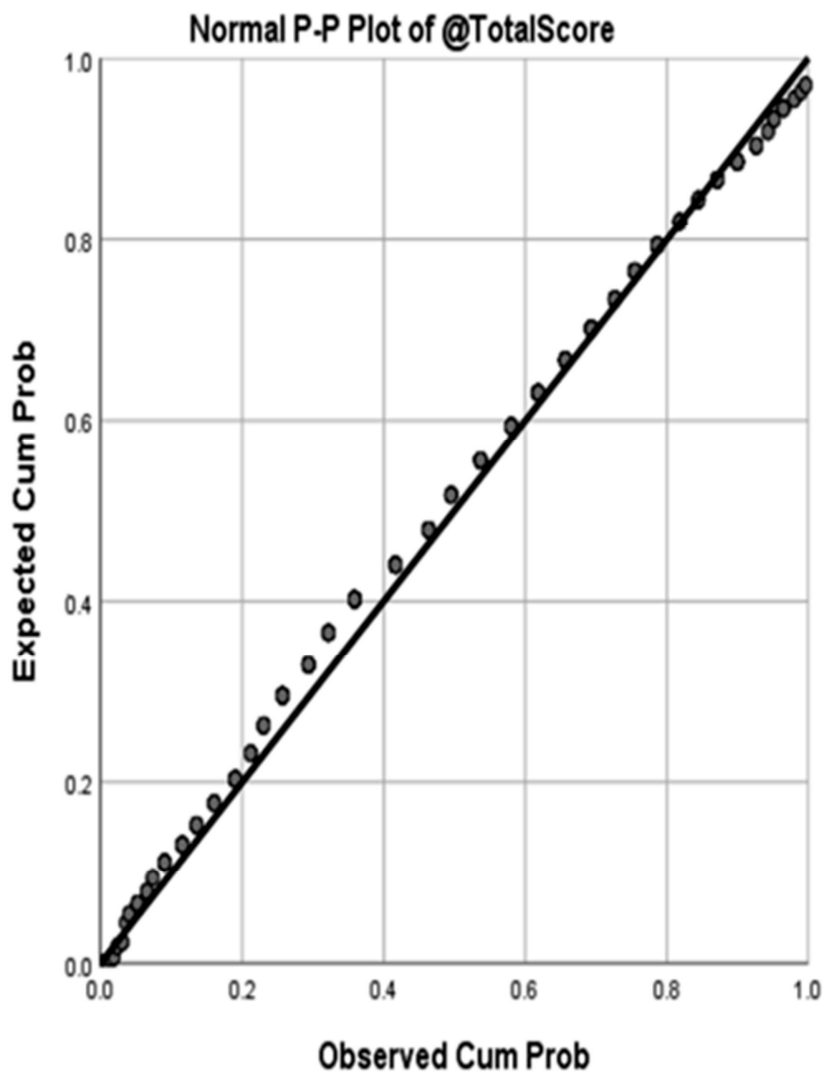

Figure 3. Normal P-P Plot of Score.

It can be seen from the above 5 that the standard deviation of school B is 9.70808 and school A is 10.89697 , that is, the dispersion of the school B is less than that of school A. The independent sample t-test $\mathrm{P}$ (sig.) $=0.619<0.05$ shows that there is no significant difference between the two schools in their attitudes towards science education in senior high school English textbooks. Therefore, this study reject the hypothesis 1 "There is significant difference between the two schools in students' attitude towards science education in high school English textbooks".

From figure 3 , it can be seen that the total scores of 300 students in this questionnaire are normal distribution approximately.

Table 6. Correlations between grouping variables and attention (Total score).

\begin{tabular}{llll}
\hline & & & Total score \\
\hline \multirow{3}{*}{ School } & Pearson & Correlation coefficient & 0.029 \\
& Correlation & Sig. (2-tailed) & 0.619 \\
& & N & 300 \\
Grade & Pearson & Correlation coefficient & 0.027 \\
& Correlation & Sig. (2-tailed) & 0.639 \\
& & N & 300 \\
Gender & Pearson & Correlation coefficient & $0.152^{* *}$ \\
& Correlation & Sig. (2-tailed) & 0.009 \\
& & N & 300 \\
Age & Pearson & Correlation coefficient & -0.039 \\
& Correlation & Sig. (2-tailed) & 0.502 \\
Class & & N & 300 \\
Type & Pearson & Correlation coefficient & 0.098 \\
& Correlation & Sig. (2-tailed) & 0.092 \\
\hline
\end{tabular}

*. Correlation is significant at the 0.01 level (2-tailed).

Table 6 shows that the correlation of students' total score to science education and their school, gender, ages, grades and class type. Table 7 shows that the values and relative intensities of correlation coefficient.

Table 7. Values and relative intensities of $R$.

\begin{tabular}{llllll}
\hline \multicolumn{1}{l}{ Values and Relative Intensities of $R$} & & & \\
\hline The Value of $R$ & $\mathbf{0 . 0 0 \sim 0 . 1 9}$ & $\mathbf{0 . 2 0} \sim \mathbf{0 . 3 9}$ & $\mathbf{0 . 4 0 \sim 0 . 6 9}$ & $\mathbf{0 . 7 0} \mathbf{0 . 8 9}$ & $\mathbf{0 . 9 0 \sim 1 . 0 0}$ \\
\hline Intensity Judgment & Very Low & Low & Moderate & High & Strongly High \\
\hline
\end{tabular}

From table 6 and 7 , it can be seen that the correlation coefficients of students' total score to science education and their school, ages, grades and class type are less than 0.19 . Among them, the correlation coefficients of students' total score to science education and their school, grades and class type are less positive, therefore, the hypothesis $2,4,6$ need to be accepted; the correlation coefficients of students' total score to science education and their age is negative, therefore, the hypothesis 5 need to be rejected. In other words, the attention (score) of students towards science education in English textbooks of Chinese senior high school shows a downward trend with the growth of age. The positive correlation of students' total score to science education and their gender is very low, therefore, the hypothesis 3 can be accepted. And the common characteristic is the correlation is very weak among them.

\subsection{Descriptive Analysis Results}

The necessity, content, multimodal integration form, students' preference for multimodality and the English teachers' ability of using multimodality to teach science education in students' opinion will be analyzed respectively in this part.

\section{Item 1. Necessity of science education}

First of all, it analyzes the students' attitude towards necessity of science education in English textbooks of Chinese senior high school, just as following table 8 . 
Table 8. Necessity of science education

\begin{tabular}{|c|c|c|c|c|c|c|c|c|}
\hline Qs & School & Mean & S. D. & Very disagree & Disagree & Not sure & Quite agree & Strongly agree \\
\hline \multirow{3}{*}{ Q6 } & School A & 4.08 & 0.909 & $5(3.3 \%)$ & $3(2.0 \%)$ & $17(11.3 \%)$ & $75(50.0 \%)$ & $50(33.3 \%)$ \\
\hline & School B & 4.38 & 0.672 & $1(0.7 \%)$ & $2(1.3 \%)$ & $4(2.7 \%)$ & $75(50.0 \%)$ & $68(45.3 \%)$ \\
\hline & Total & 4.23 & 0.812 & $6(2.0 \%)$ & $5(1.7 \%)$ & $21(7.0 \%)$ & $150(50.0 \%)$ & $118(39.3 \%)$ \\
\hline \multirow[t]{2}{*}{ Q7 } & School B & 4.19 & 0.953 & $2(1.3 \%)$ & $8(5.3 \%)$ & $20(13.3 \%)$ & $49(32.7 \%)$ & $71(47.3 \%)$ \\
\hline & Total & 4.17 & 0.976 & $7(2.3 \%)$ & $12(4.0 \%)$ & $43(14.3 \%)$ & $98(32.7 \%)$ & $140(46.7 \%)$ \\
\hline \multirow{2}{*}{ Q8 } & School A & 4.29 & 0.936 & $4(2.7 \%)$ & $4(2.7 \%)$ & $14(9.3 \%)$ & $51(34.0 \%)$ & $77(51.3 \%)$ \\
\hline & Total & 4.25 & 0.888 & $5(1.7 \%)$ & $8(2.7 \%)$ & $36(12.0 \%)$ & $110(36.7 \%)$ & $141(47.0 \%)$ \\
\hline \multirow{3}{*}{ Q9 } & School A & 4.05 & 1.077 & $7(4.7 \%)$ & $6(4.0 \%)$ & $23(15.3 \%)$ & $51(34.0 \%)$ & $63(42.0 \%)$ \\
\hline & School B & 4.11 & 0.998 & $5(3.3 \%)$ & $5(3.3 \%)$ & $22(14.7 \%)$ & $55(36.7 \%)$ & $63(42.0 \%)$ \\
\hline & Total & 4.08 & 1.037 & $12(4.0 \%)$ & $11(3.7 \%)$ & $45(15.0 \%)$ & $106(35.3 \%)$ & $126(42.0 \%)$ \\
\hline
\end{tabular}

Table 8 reveals that the students' attitude towards necessity of science education in English textbooks of Chinese senior high school. It can be seen that $89.3 \%$ of students from Chinese senior high school agree with the issue of "Q6 I think it is necessary for English textbooks of Chinese senior high school to include science education", 39.3\% strongly agree and $7.0 \%$ of students from Chinese senior high school are not sure among them. And the mean value is 4.23 , and the standard deviation is 0.812 . In other words, the majority of students hold a positive attitude towards the necessity of science education in English textbooks of Chinese senior high school. Specifically, the dispersion of School B (Mean=4.38; $\mathrm{S}$. D. $=0.672)$ is lower than that of school A, and the mean is higher than that of school A (Mean=4.08; S.D.=0.909). The reason of this result is that the proportion of students who hold "not sure" on this question in school $\mathrm{A}$ is more than that in school B. $79.4 \%$ of students holds that science education in textbook is closely related to their study and future life, and $14.3 \%$ of them are not sure the relationship between the content of science education and their daily life. The reason why the discrete characteristic of students' attitudes towards this question is that this part of students who are not sure its relationship. Science and life are inseparable, science can be seen everywhere in life. On this question, there is not much difference in the mean and dispersion between school A (Mean=4.15; S.D. $=1.002)$ and school B (Mean=4.19; S.D. $=0.953$ ). $83.7 \%$ of students believes that the content of science education in English textbooks of Chinese senior high school is one of the important ways to cultivate international vision and inherit scientific culture, and $12 \%$ of them are not sure; the mean of this question is the highest one in this part (Mean=4.25), and the standard deviation is 0.888 . That is to say, most students think that there is a positive correlation between science education and the broadening of their international vision and the inheritance of science culture without considering other objective factors. Specifically, the dispersion of students' attitude towards this problem in school B (Mean=4.21; S.D. $=0.838)$ is more concentrated than that in school A (Mean=4.29; S.D. $=0.936)$, but the mean is lower than school A slightly. $77.3 \%$ of students in Chinese senior high school holds that learning Chinese science education through English teaching is helpful to cultivate our patriotic enthusiasm and national pride, $15.0 \%$ not sure, and $7.7 \%$ disagree $($ Mean $=4.08$, S.D. $=1.037)$. In other words, students' attitude towards necessity of science education in English textbooks of Chinese senior high school is more focused than others. Among them, the mean of School A is 4.05 and the standard deviation is 1.077; the mean of School B is 4.11 and the standard deviation is 0.998 . The importance of science education is self-evident. English is a language for communication with various countries in the world, students can understand and learn foreign excellent science, broaden their international vision, and promote the inheritance of excellent science and culture through communication. Through this part of data and analysis, it can be seen that Chinese senior high school students have a clear understanding of the necessity of science education content in English textbooks of Chinese senior high school. Students are also can feel the powerful power of science through the teaching of science education, which is also more conducive to the cultivation of their scientific exploration ability and scientific literacy.

Item 2. Content of science education

Table 9. Content of science education.

\begin{tabular}{|c|c|c|c|c|c|c|c|c|}
\hline Qs & School & Mean & S. D. & Very disagree & Disagree & Not sure & Quite agree & Strongly agree \\
\hline \multirow{3}{*}{ Q10 } & School A & 4.04 & 0.962 & $4(2.7 \%)$ & $6(4.0 \%)$ & $24(16.0 \%)$ & $62(41.3 \%)$ & $54(36.0 \%)$ \\
\hline & School B & 4.25 & 0.851 & $1(0.7 \%)$ & $3(2.0 \%)$ & $25(16.7 \%)$ & $50(33.3 \%)$ & $71(47.3 \%)$ \\
\hline & Total & 4.14 & 0.912 & $5(1.7 \%)$ & $9(3.0 \%)$ & $49(16.3 \%)$ & $112(37.3 \%)$ & $125(41.7 \%)$ \\
\hline \multirow{3}{*}{ Q11 } & School A & 3.19 & 1.103 & $10(6.7 \%)$ & $31(20.7 \%)$ & $47(31.3 \%)$ & $44(29.3 \%)$ & $18(12.0 \%)$ \\
\hline & School B & 2.99 & 1.087 & $8(5.3 \%)$ & $50(33.3 \%)$ & $43(28.7 \%)$ & $34(22.7 \%)$ & $15(10.0 \%)$ \\
\hline & Total & 3.09 & 1.098 & $18(6.0 \%)$ & $81(27.0 \%)$ & $90(30.0 \%)$ & $78(26.0 \%)$ & $33(11.0 \%)$ \\
\hline \multirow[t]{2}{*}{ Q12 } & School B & 4.17 & 0.825 & $2(1.3 \%)$ & $2(1.3 \%)$ & $22(14.7 \%)$ & $66(44.0 \%)$ & $58(38.7 \%)$ \\
\hline & Total & 4.07 & 0.958 & $7(2.3 \%)$ & $12(4.0 \%)$ & $50(16.7 \%)$ & $116(38.7 \%)$ & $115(38.3 \%)$ \\
\hline
\end{tabular}


Table 9 reveals that the students' attitude towards content of science education in English textbooks of Chinese senior high school. It can be seen that $79.0 \%$ of students in Chinese high school agree biological science education, science information technology education, and history of science and technology should be important contents of science education considering covid-19 impact of education and content, and $16.3 \%$ not sure. Specifically speaking, $80.6 \%$ of students from school A (Mean=4.04, S.D. $=0.962$ ) hold the opinion of agreeing, school B 77.3\% (Mean=4.25, S.D. $=0.851) ; 6.7 \%$ of students from school A disagree this opinion and school B accounts for $2.7 \%$. The covid-19 is undoubtedly the most objective test of the science and technology in the whole world and reflect the importance of biological science education from the objective level. As the 2020 covid-19 continued to spring, the teachers and students of elementary education began to teach and learn through information technology, WeChat, QQ, Tencent conference and other remote information technology become the best way for students to acquire knowledge and teacher to teach knowledge. However, it requires that teachers need to guide students to realize the importance of biological science education, science information technology education, and history of science and technology in English textbooks of Chinese senior high school. For the view of "I think the content and form of science education in English textbooks of Chinese senior high school are very rich", 37.0\% of students agree with it, $30.0 \%$ not sure, and 33.0\% disagree (Mean=3.09, S.D. $=1.098)$. The students' attitude is more discrete. It shows that students of $1 / 3$ may not know much about the content and integrated form of science education in Chinese senior high school English textbooks. More specifically, the standard deviation of school $\mathrm{A}$ is 1.103 , mean is 3.19 ; while the standard deviation of school B is 1.087 and the mean is 2.99 . This part of students can realize the importance of science education, but they can not to extract them in their learning. For the view of "I think it is very necessary to add the development history of China's science and technology and the content of Chinese science education to the current English textbooks of Chinese senior high school in China", $76.0 \%$ of students agree, $16.7 \%$ not sure, and 6.3 disagree (Mean=4.07, S.D. $=0.958$ ). Among them, the students of holding the opinion of agreeing from school A account for $71.3 \%$, which is higher than school B $(81.7 \%)$; the students of holding the opinion of disagreeing from school A account for $10.0 \%$, which is higher than school B $(2.6 \%)$. And the dispersion of students' attitude towards this problem in school B (Mean=4.17, S.D. $=0.825)$ is less than that in school A (Mean=3.96, S.D.=1.067). Students' attitude towards the richness of the content and integrated form of science education in English textbooks of Chinese senior high school has a high degree of dispersion compared with the the points of biological science education, science information technology education, and history of science and technology should be important contents of science education and the necessity of adding the development history of China's science and technology and the content of Chinese science education to the current English textbooks of Chinese senior high school in China.

Item 3. Multimodal integration of science education

Table 10. Multimodal integration of science education.

\begin{tabular}{|c|c|c|c|c|c|c|c|c|}
\hline Qs & School & Mean & S. D. & Very disagree & Disagree & Not sure & Quite agree & Strongly agree \\
\hline \multirow{3}{*}{ Q13 } & School A & 3.49 & 1.191 & $13(8.7 \%)$ & $17(11.3 \%)$ & $35(23.3 \%)$ & $54(36.0 \%)$ & $31(20.7 \%)$ \\
\hline & School B & 3.96 & 0.926 & $3(2.0 \%)$ & $6(4.0 \%)$ & $31(20.7 \%)$ & $64(42.7 \%)$ & $46(30.7 \%)$ \\
\hline & Total & 3.72 & 1.091 & $16(5.3 \%)$ & $23(7.7 \%)$ & $66(22.0 \%)$ & $118(39.3 \%)$ & $77(25.7 \%)$ \\
\hline \multirow{3}{*}{ Q14 } & School A & 4.69 & 0.667 & $1(0.7 \%)$ & $2(1.3 \%)$ & $5(3.3 \%)$ & $27(18.0 \%)$ & $115(76.7 \%)$ \\
\hline & School B & 4.69 & 0.696 & $2(1.3 \%)$ & $1(0.7 \%)$ & $5(3.3 \%)$ & $26(17.3 \%)$ & $116(77.3 \%)$ \\
\hline & Total & 4.69 & 0.681 & $3(1.0 \%)$ & $3(1.0 \%)$ & $10(3.3 \%)$ & $53(17.7 \%)$ & $231(77.0 \%)$ \\
\hline \multirow[t]{2}{*}{ Q15 } & School B & 4.29 & 0.877 & $2(1.3 \%)$ & $6(4.0 \%)$ & $12(8.0 \%)$ & $57(38.0 \%)$ & $73(48.7 \%)$ \\
\hline & Total & 4.34 & 0.845 & $3(1.0 \%)$ & $8(2.7 \%)$ & $31(10.3 \%)$ & $99(33.0 \%)$ & $159(53.0 \%)$ \\
\hline \multirow{3}{*}{ Q16 } & School A & 4.24 & 0.910 & $2(1.3 \%)$ & $4(2.7 \%)$ & $24(16.0 \%)$ & $46(30.7 \%)$ & $74(49.3 \%)$ \\
\hline & School B & 4.29 & 0.824 & $1(0.7 \%)$ & $3(2.0 \%)$ & $20(13.3 \%)$ & $53(35.3 \%)$ & $73(48.7 \%)$ \\
\hline & Total & 4.27 & 0.867 & $3(1.0 \%)$ & $7(2.3 \%)$ & $44(14.7 \%)$ & $99(33.0 \%)$ & $147(49.0 \%)$ \\
\hline \multirow[b]{2}{*}{ Q17 } & School A & 3.83 & 1.102 & $7(4.7 \%)$ & $12(8.0 \%)$ & $27(18.0 \%)$ & $57(38.0 \%)$ & $47(31.3 \%)$ \\
\hline & School B & 4.11 & 0.899 & $4(2.7 \%)$ & $3(2.0 \%)$ & $20(13.3 \%)$ & $69(46.0 \%)$ & $54(36.0 \%)$ \\
\hline \multirow{3}{*}{ Q18 } & School A & 4.21 & 0.957 & $4(2.7 \%)$ & $2(1.3 \%)$ & $26(17.3 \%)$ & $45(30.0 \%)$ & $73(48.7 \%)$ \\
\hline & School B & 4.30 & 0.758 & $0(0.0 \%)$ & $1(0.7 \%)$ & $24(16.0 \%)$ & $54(36.0 \%)$ & $71(47.3 \%)$ \\
\hline & Total & 4.25 & 0.863 & $4(1.3 \%)$ & $3(1.0 \%)$ & $50(16.7 \%)$ & $99(33.0 \%)$ & $144(48.0 \%)$ \\
\hline \multirow{3}{*}{ Q19 } & School A & 3.89 & 0.970 & $4(2.7 \%)$ & $3(2.0 \%)$ & $46(30.7 \%)$ & $49(32.7 \%)$ & $48(32.0 \%)$ \\
\hline & School B & 4.13 & 0.797 & $0(0.0 \%)$ & $2(1.3 \%)$ & $33(22.0 \%)$ & $59(39.3 \%)$ & $56(37.3 \%)$ \\
\hline & Total & 4.01 & 0.894 & $4(1.3 \%)$ & $5(1.7 \%)$ & $79(26.3 \%)$ & $108(36.0 \%)$ & $104(34.7 \%)$ \\
\hline
\end{tabular}

The students' attitude towards the multimodal integration of science education in English textbooks of Chinese senior high school is the focus of this questionnaire. Multimodality, a common form in daily life now, is composed of audio, video, image and color are single modality. Among them, audio modal can make the received data convey to the brain through humans' 
auditory system, and video modality can transfer the material to be received through the humans' visual system, and color is assisted. The perceptual system forms a modal of clearer understanding of specific corpus images. However, due to the inherent characteristics of textbooks for a long time and the lag of updating, students use these modals but do not know their professional terms. Therefore, in the part of multimodal integration form of science education, researchers divide it into two aspects: guide students to understand what is multimodality and investigate the students' attitude towards what positive role does multimodal integration form of science education have.

Table 10 reveals that the students' attitude towards adopting multimodal integration of science education in English textbooks of Chinese senior high school. It can be seen that students of Chinese senior high school are more eager to learn science education through multimodal forms such as audio, video, images and so on. $65.0 \%$ of students agree that " $Q 13 I$ think English textbooks of Chinese senior high school should add basic English terminology expression and matching exercises to the development of science and technology in China", $13.0 \%$ disagree; mean is 3.72 with the biggest standard deviation 1.091 among this part of views. And the reason why the dispersion of students' attitude from school B is less than school A (Mean=3.49, S.D.=1.191) is that the percentage of disagreeing from school A is more than school B (Mean=3.96, S.D. $=0.926$ ) . $94.7 \%$ of students agree that " $Q 14$ I think English textbooks of Chinese senior high school should add dialogues, video clips, and other English videos related to science education", mean is 4.69, S.D. $=0.681$. And the mean of school A is same as school B. In other words, students attitude towards presenting science education by means of video is the most focused. $86.0 \%$ of students agree that " $Q 15$ I think English textbooks of Chinese senior high school should add news reports, monologues and other English audio related to science education", $10.3 \%$ not sure, mean is 4.34 and standard deviation is 0.845 . Among them, the mean of students from school $\mathrm{A}$ is 4.40 , standard deviation is 0.811 ; the mean of students from school B is 4.29 , standard deviation is 0.877 . $82.0 \%$ of students agree that "Q16 I think English textbooks of Chinese senior high school should add posters of science and technology, icons of science and technology, propaganda wall of science and culture and other English images and texts related to science education", $14.7 \%$ not sure (Mean $=4.27$, S.D. $=0.867$ ). There is the similar characteristic of dispersion between school A and school B. The students' attitude towards question 17 (Mean=3.97, S.D.=1.013) is similar to that of question 13, which is more discrete than others. Specifically, the mean of school A is 3.83, which is lower than school B (Mean=4.11). The standard deviation of school A is 1.102, which is lower than school B in the characteristic of dispersion (S.D. $=0.899)$. In other words, the students from school B is more concentrate than school A slightly. It shows that students prefer to learn science education in the modality of video, audio and image. For students, multimodal presentation of science education is conducive to their deep impression and understanding of science education. For this view, $81 \%$ of the students agree and $16.7 \%$ of the students are uncertain (Mean=4.25, S.D. $=0.863$ ). Similarly, two groups attitude of students towards this question from school A and school B is consistent basically. In opinion of "I think the approach of multimodality to science education will be emphasized in the future", its mean is 4.01 and standard deviation is 0.894 . Most of the students think that the multimodal integration will be attached importance in the future. But the mean of school B is higher than school A, the dispersion is lower than school A.

Item 4. Students' preference for science education

Table 11. Students' preference for Science Education.

\begin{tabular}{|c|c|c|c|c|c|c|c|c|}
\hline Qs & School & Mean & S. D. & Very disagree & Disagree & Not sure & Quite agree & Strongly agree \\
\hline \multirow{3}{*}{ Q20 } & School A & 3.49 & 1.035 & $4(2.7 \%)$ & $19(12.7 \%)$ & $57(38.0 \%)$ & $40(26.7 \%)$ & $30(20.0 \%)$ \\
\hline & School B & 3.78 & 1.002 & $2(1.3 \%)$ & $16(10.7 \%)$ & $35(23.3 \%)$ & $57(38.0 \%)$ & $40(26.7 \%)$ \\
\hline & Total & 3.63 & 1.027 & $6(2.0 \%)$ & $35(11.7 \%)$ & $92(30.7 \%)$ & $97(32.3 \%)$ & $70(23.3 \%)$ \\
\hline \multirow{3}{*}{ Q21 } & School A & 4.19 & 0.857 & $1(0.7 \%)$ & $5(3.3 \%)$ & $22(14.7 \%)$ & $58(38.7 \%)$ & $64(42.7 \%)$ \\
\hline & School B & 3.97 & 0.999 & $4(2.7 \%)$ & $9(6.0 \%)$ & $26(17.3 \%)$ & $60(40.0 \%)$ & $51(34.0 \%)$ \\
\hline & Total & 4.08 & 0.936 & $5(1.7 \%)$ & $14(4.7 \%)$ & $48(16.0 \%)$ & $118(39.3 \%)$ & $115(38.3 \%)$ \\
\hline \multirow[t]{2}{*}{ Q22 } & School B & 4.26 & 0.944 & $5(3.3 \%)$ & $1(0.7 \%)$ & $19(12.7 \%)$ & $50(33.3 \%)$ & $75(50.0 \%)$ \\
\hline & Total & 4.13 & 0.947 & $7(2.3 \%)$ & $9(3.0 \%)$ & $48(16.0 \%)$ & $110(36.7 \%)$ & $126(42.0 \%)$ \\
\hline
\end{tabular}

To a large extent, the choice of educational content should be considered from all aspects, such as students' preferences, the relevance between the content and students' life, and the positive role of the educational content in the country. The three questions from Q20 to Q22 are about students' preferences for science education. It can be seen from the data in the table 11 that the students' opinions on the issue of whether they are more interested in science education than other contents in English textbooks of Chinese senior high school are scattered, with the standard deviation of 1.027 (Mean=3.63). Specifically, the attitude of school A is more scattered than school B. The purpose of science education is to cultivate and form better scientific literacy. In this regard, students believe that they should take the initiative to cultivate their translation ability for the development of modern and contemporary Chinese science and technology and the related content of ancient Chinese history of science and technology, and improve their scientific literacy (Mean=4.13, S.D.=0.947).

Item 5. Students' attitude towards teachers' ability to teach science education in multimodality

Finally, it is a survey of students' attitudes towards the current English teachers' mastery and adoption of multimodal integration to teach science education. It can be seen from the table 12 that the opinions of the students are relatively discrete. 
Table 12. Students' attitude towards teachers' ability to teach science education in multimodality.

\begin{tabular}{lllllllll}
\hline Qs & School & Mean & S. D. & Very disagree & Disagree & Not sure & Quite agree & Strongly agree \\
\hline & School A & 4.02 & 0.886 & $3(2.0 \%)$ & $3(2.0 \%)$ & $30(20.0 \%)$ & $66(44.0 \%)$ & $48(32.0 \%)$ \\
Q23 & School B & 3.67 & 1.179 & $11(7.3 \%)$ & $12(8.0 \%)$ & $34(22.7 \%)$ & $51(34.0 \%)$ & $42(28.0 \%)$ \\
& Total & 3.85 & 1.055 & $14(4.7 \%)$ & $15(5.0 \%)$ & $64(21.3 \%)$ & $117(39.0 \%)$ & $90(30.0 \%)$ \\
& School A & 4.09 & 0.944 & $3(2.0 \%)$ & $5(3.3 \%)$ & $27(18.0 \%)$ & $55(36.7 \%)$ & $60(40.0 \%)$ \\
Q24 & School B & 3.54 & 1.304 & $17(11.3 \%)$ & $16(10.7 \%)$ & $27(18.0 \%)$ & $49(32.7 \%)$ & $41(27.3 \%)$ \\
& Total & 3.82 & 1.169 & $20(6.7 \%)$ & $21(7.0 \%)$ & $54(18.0 \%)$ & $104(34.7 \%)$ & $101(33.7 \%)$ \\
& School A & 3.96 & 1.055 & $4(2.7 \%)$ & $11(7.3 \%)$ & $29(19.3 \%)$ & $49(32.7 \%)$ & $57(38.0 \%)$ \\
Q25 & School B & 3.58 & 1.312 & $15(10.0 \%)$ & $18(12.0 \%)$ & $29(19.3 \%)$ & $41(27.3 \%)$ & $47(31.3 \%)$ \\
& Total & 3.77 & 1.204 & $19(6.3 \%)$ & $29(9.7 \%)$ & $58(19.3 \%)$ & $90(30.0 \%)$ & $104(34.7 \%)$ \\
\hline
\end{tabular}

Among them, the mean of students' attitude towards "I think our English teachers should master the way of multimodality to present the characteristics and forms of science education content in English textbooks of Chinese senior high school" is the largest one (Mean=3.85, S.D. $=1.055) ; 69.0 \%$ of students agree, $21.3 \%$ not sure, and nearly $10 \%$ of students disagree. In this question, the dispersion of students from school $\mathrm{A}$ is lower than school B. The reason why is that there are $15.3 \%$ of students from school B hold the opinion of disagreeing. The mean of attitude towards "In my opinion, in addition to the science education in textbooks, our English teachers can also supplement the science education that are not involved in the latest scientific and technological progress" is the lowest one (Mean=3.77, S.D.=1.204). The dispersion of students from two schools is similar to question 23, that is to say, school A is lower than school B. It shows that students from school B are more skeptical of their English teachers' ability to supplement the content of science education that is not included in textbooks than school A.

In the analysis above, it can be found that: schools, gender, ages, grades and class type of students are not strong positive or negative correlation with their attention to science education in English textbooks of Chinese senior high school; students' awareness of significance to science education is weak comparatively; students prefer to learn science education by using multimodality systematically; and most of students are not sure their English teachers' teaching competence by using multimodality to teach science education.

\section{Conclusion}

The characteristics of students' attitude towards science education in English textbooks of Chinese senior high school from multimodality are as following: 1) the correlation coefficients of students' total score to science education and their gender, ages, grades and class type are weak. Specially, the correlation of students' total score to science education and their ages and grades is negative correlation, the correlation of students' total score to science education and their gender and class type is positive correlation; 2) students' awareness and understanding towards the necessity of science education in English textbooks of Chinese senior high school still need to be improved; 3) The richness of the content and form of science education in the current English textbooks of Chinese senior high school needs to be improved; 4) students prefer the combination of several modals to be used in the process of learning, such as audios, videos, images, colors and texts; 5) students hope that they can learn more knowledge about science education systematically, such as the English terms of science technology, the history of science technology in China and abroad, and etc.; 6) the teaching competence of teachers using multimodality to teach science education needs to be improved. The main findings are: 1) students prefer the combination of audios, videos, images, colors and texts to be used in English learning; 2) students hope that they can learn more knowledge about science education systematically under the use of multimodality.

\section{Suggestions}

To solve problems above, The suggestions of this study are:

On the one hand, students should: 1) pay attention to the significance of necessity of science education in English textbooks of Chinese senior high school under the background of examination-oriented education; 2) pay attention to improve science education awareness and scientific technology skills from multimodality teaching class; 3 ) pay attention to improve English reading skills to enlarge the diversity of scientific learning skills.

On the other hand, English teachers should: 1) pay attention to use multimodality to teach science education in the process of teaching, so as to improve students' understanding to the knowledge of science and students' writing under the topics of science; 2) pay attention to teach systematically. Take seismograph as an example, it can be considered the presentation of process from ancient to modern, so as to students form a whole understanding to it; 3 ) pay attention to enrich their teaching competence using multimodality to teach educational contents.

The limitations of this study lie in the following: 1) the students in Chinese senior high schools are from Henan Province in China. The only one province is not enough to fully represent the overall situation of all students in Chinese senior high schools. The number of questions collected by the researcher is limited, and the aspects of questions involved are not wide enough. 2) some students may not choose the answer in their real mind, even though the researcher already stressed that there is no privacy involved in this questionnaire. 3) students of senior three have learned a complete set of English textbooks in Chinese senior high school, and their 
understanding and mastery of the integration form and content of science education is higher than that of senior one and senior two to a certain extent. Due to the heavy academic workload and other reasons for students of senior grade three, this study only investigated students groups of senior grade one and senior grade two. Therefore, the survey results are not as comprehensive as it should be. However, it is undoubtedly of great significance for the reference to science education in
English textbooks of Chinese senior high school from multimodality. From view of the above limitations, this study will make further improvements: 1) expand the scope and volume of investigation, especially the students group of senior three to be more scientific; 2) conduct in-depth interviews with respondents deeply to understand their attitudes towards using multimodality to teach science education.

\section{Appendix: Questionnaires for Students}

Dear students,

Hello, everyone! Thank you for participating in this survey. This questionnaire is filled in anonymously, only as part of the paper, not for other purposes, please rest assured to participate. There is no right or wrong in the answers to the questionnaire. Please tick " $\sqrt{ }$ " under your options according to your actual situation. Your opinion is important to this study. Please don't miss any questions in the questionnaire. Finally, thank you for your participation in this survey.

Part 1. Personal Information Survey

1. Your school:_2. Your grade:_3. Your gender:

4. Your age:_5. Your class type (Science / Liberal Art / Neither):

Part 2. The following questions describe the content of science education in English textbooks of Chinese senior high school. Please choose the degree of recognition according to the actual situation and your own feelings, and give real answers to each question and tick $(\sqrt{ })$ in the corresponding choice.

(Attention: $A=$ Strongly Agree, $B=$ Quite Agree, $C=$ Not Sure, $D=$ Disagree, E=Very Disagree)

Topics

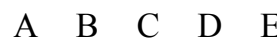

6. I think it is necessary for English textbooks of Chinese senior high school to include science education.

7. I think science education in textbook is closely related to our study and future life.

8. I think the content of science education in English textbooks of Chinese senior high school is one of the important ways to cultivate our international vision and inherit scientific culture.

9. I think learning Chinese science education through English teaching of Chinese senior high school is helpful to cultivate our patriotic enthusiasm and national pride.

10. Considering covid-19 impact of education and content, I believe biological science education, science information technology education, and history of science and technology should be important contents of science education.

11. I think the content and form of science education in English textbooks of Chinese senior high school are very rich.

12. I think it is very necessary to add the development history of China's science and technology and the content of Chinese science education to the current English textbooks of Chinese senior high school in China.

13. I think English textbooks of Chinese senior high school should add basic English terminology expression and matching exercises to the development of science and technology in China.

14. I think English textbooks of Chinese senior high school should add dialogues, video clips, and other English videos related to science education.

15. I think English textbooks of Chinese senior high school should add news reports, monologues and other English audio related to science education.

16. I think English textbooks of Chinese senior high school should add posters of science and technology, icons of science and technology, propaganda wall of science and culture and other English images and texts related to science education.

17. I think English textbooks of Chinese senior high school should add English exercises related to 
science education, such as epidemic prevention through science.

18. I think the approach of multimodality to present the content of science education can deepen our understanding of science.

19. I think the approach of multimodality to science education will be emphasized in the future.

20. I think we are more interested in science education than other contents in English textbooks of Chinese senior high school.

21. I think the study of science education in English textbooks of Chinese senior high school is conducive to the cultivation of our cross-cultural communication ability and scientific literacy.

22. I think we should take the initiative to cultivate our own translation ability for the development of Chinese science and technology in modern and contemporary and the related science and technology of ancient Chinese history, so as to improve our scientific literacy.

23. I think our English teachers should master the way of multimodality to present the characteristics and forms of science education content in English textbooks of Chinese senior high school.

24. I think our English teachers can accurately extract the content of science education in English textbooks of Chinese senior high school and study with us.

25. In my opinion, in addition to the science education in textbooks, our English teachers can also supplement the science education that are not involved in the latest scientific and technological progress.

\section{Acknowledgements}

We are grateful for the financial support from Social Science Foundation of Ministry of Education (No. 17YJA740032) and He'nan Social Sciences Planning Project (No. 2018BYY018).

\section{References}

[1] Yu Bi. (2015). The Application of Multi-modal Discourse Analysis to Junior Middle School English Vocabulary Teaching - A Case Study of No.66 Middle School in Urumqi. Xinjiang Normal University, 20.

[2] Liuyan Xin. (2015). On the Application of Multimodal Discourse Analysis to English Vocabulary Teaching in High School. Minnan Normal University, 12-15.

[3] Wenwen Qu. (2016). The Application of Multimodal Theory to English Vocabulary Teaching in Chinese Senior High School. China University of Petroleum (East China).

[4] Xiaoxian Liao. (2016). An Experimental Study of English Vocabulary Multimodal Teaching in Junior Middle School English Vocabulary Teaching. Guangzhou University.

[5] Xue Chen. (2015). A Study of College English Writing Instruction Based on multimodality. Shenyang Normal University.

[6] Juan Du. (2019). A Multimodal Discourse Analysis of Senior High School. Lanzhou University of Technology, 30-65.

[7] Weiqing Cui. (2012). Multimodal Discourse Analysis of PEP in English Textbooks Senior High School -- "Pre-reading" and "Reading". Zhangzhou Normal University, 13-19.
[8] Jigang Cai. (2020). Reflection on the lack of scientific literacy in college English teaching under the epidemic situation. Contemporary Foreign Language Studies, (2): 39-47.

[9] Xiaotang Cheng. (2002). Analysis and design of English textbooks. Beijing: Foreign Language Teaching and Research Press, 15, 54-64.

[10] Bin Lu, Shengyan Shi. (2020). A Study on Science Education of Chinese English Textbooks in Chinese Senior High School from the Perspective of Multimodality. Education Journal, (6): 179-194.

[11] Kress, G. (2010). Multimodality: A Social Semiotic Approach to Contemporary Communication. London: Routledge, 79.

[12] Ou Shi. (2019). Textbook Research Methodology. Guangdong Education Press: 28-29.

[13] Xia Tan, Guohua Liu. (2015). Research on the Countermeasures of science education based on the improvement of public science literacy. Education Exploration, (10): $28-34$

[14] Yongsheng Zhu. (2007). Theory and Methodology of Multimodal Discourse Analysis. Foreign Language Research, (5): 82-86.

[15] Kress, G\& Van Leeuwen, T. (2001). Multimodal Discourse: The Mode and Media of Contemporary Communication. London: Arnold, 21-22.

[16] Van Leeuwen, T. (2006). Towards a Semiotics of Typography. Information Design Journal, 14(2): 139-155.

[17] Xiaotang Cheng. (2002). Analysis and design of English textbooks. Beijing: Foreign Language Teaching and Research Press, 10-15. 